\title{
Does PBL deliver constructive collaboration for students in interprofessional tutorial groups?
}

Endang Lestari ${ }^{i^{*}}$, Renée E. Stalmeijer ${ }^{2}$, Doni Widyandana ${ }^{3}$ and Albert Scherpbier ${ }^{2}$

\begin{abstract}
Background: Training health professional students in teamwork is recognized as an important step to create interprofessional collaboration in the clinical workplace. Interprofessional problem-based learning (PBL) is one learning approach that has been proposed to provide students with the opportunity to develop the necessary skills to work collaboratively with various health professionals. This study aimed to explore the extent to which students in interprofessional tutorial groups demonstrate constructive collaboration during group discussions.

Methods: Students ( $N=52)$ from the Medical, Midwifery and Nursing programmes took part in the study. Videorecordings were made of interprofessional PBL discussions $(N=40)$ in five groups, eight videos per group. Over a period of 4 weeks, participants discussed four scenarios concerned with the reproductive system. The resulting $67 \mathrm{~h}$ of video data were analysed qualitatively. To ensure inter-rater reliability, two tutors assessed the students' constructive, collaborative activities using the Maastricht Peer-Activity Rating Scale (MPARS). Finally, to gain an understanding of students' perceptions of their performance and participation in the interprofessional PBL tutorial, we organized three uni-professional focus groups (FGs) at the end of pilot project.
\end{abstract}

Results: The translated MPARS was reliable (Kappa coefficient $0.01-0.20$ and $p<0.05$ ). Students were actively involved in the discussion and contributed to a better understanding regardless of their professional background. Group members from different professions complemented one another in solving learning issues. They were open, feeling free to question and argue from the viewpoint of their own profession, and also understood their strengths and limitations. The statistical test of the scores for constructive and collaborative activities indicated a significant difference between students and the various healthcare professionals, $p=0.000$, with medical students scoring highest on both activities. Focus groups further clarified some of the observed dynamics.

Conclusion: Implementing interprofessional PBL could motivate students to engage collaboratively in coconstructing knowledge to solve the patients' problem. Medical students scored highest on constructive and collaborative activities.

Keywords: Interprofessional problem-based learning, Maastricht peer-activity rating scale (MPARS)

\footnotetext{
* Correspondence: endanglestari@unissula.ac.id

${ }^{1}$ Medical Education Unit, Faculty of Medicine, Universitas Islam Sultan Agung,

Semarang, Indonesia

Full list of author information is available at the end of the article
}

(c) The Author(s). 2019 Open Access This article is distributed under the terms of the Creative Commons Attribution 4.0 International License (http://creativecommons.org/licenses/by/4.0/), which permits unrestricted use, distribution, and reproduction in any medium, provided you give appropriate credit to the original author(s) and the source, provide a link to the Creative Commons license, and indicate if changes were made. The Creative Commons Public Domain Dedication waiver (http://creativecommons.org/publicdomain/zero/1.0/) applies to the data made available in this article, unless otherwise stated. 


\section{Introduction}

Interprofessional collaboration in health care is considered to be a potential solution to reduce clinical error, improve patient safety and enhance the quality of patient care. Previous studies have shown that problems in collaboration and coordination between professionals can negatively affect patient outcomes, lower work satisfaction for professionals, and lead to wasted resources [17]. Previous studies report many factors that may prevent effective collaboration among professionals. These include professional factors, such as lack of knowledge about and trust in other professionals' skills and expertise, and lack of understanding of the roles of other professionals $[1,8,9]$ as well as external factors, such as professional culture, views, time constraints, problems contacting other professionals, and lack of reimbursement for collaborative work $[9,10]$.

Training health professional students to work together is recognized as an important step in creating interprofessional collaboration in the clinical workplace. Globally, the WHO supports health professions education to implement interprofessional education (IPE) [11]. IPE brings students from different health professions together to learn with, about and from each other, either in a classroom or a clinical setting [12-14]. IPE has been implemented in various educational formats, such as interprofessional ward-based training $[15,16]$, case-based discussion $[17,18]$, clinical simulation $[19,20]$, e-learning [21], and ambulatory primary care [22]. The key to effective learning in these interprofessional education programmes seems to be student interaction [23, 24]. Therefore, simply conducting shared lectures for students from different healthcare professions is unlikely to foster the attitudes and knowledge conducive to effective interprofessional teamwork [25]. Effective IPE should be interactive, collaborative, reflective, and experiential [26] and should strive to address the power relations and conflict inherent in health professional teamwork [27, 28].

Interprofessional problem-based learning (PBL) is one approach that has been proposed to provide students with the opportunities to develop the necessary skills to work collaboratively with different health professionals $[29,30]$ and effective learning approach for gaining in knowledge [31]. PBL is experiential, reflective, and intended to be interactive [32]. It provides opportunities to discuss, argue, present and hear one another's viewpoints, thus contributing to the intellectual growth of students [33]. Interprofessional PBL could result in students developing the mutual professional respect and trust that is essential in interprofessional patient-centred practice. Essential for effective PBL is that students actively construct and reconstruct their knowledge in the group by summarizing, asking critical questions and correcting misconceptions [34-37] and that students actively collaborate in the process [38].

To date, research into interprofessional PBL has, among others, explored: student satisfaction while taking part in interprofessional PBL $[39,40]$, collaborative behavior within knowledge development [41], interprofessional attitudes pre and post interprofessional PBL [42], and students' perceptions toward interprofessional PBL $[31,43]$. However, whether the working ingredients of $\mathrm{PBL}$, such as constructive and collaborative activities, still work when PBL is done within an interprofessional learning setting remains to be evaluated. The literature also reports that status factors and learners' backgrounds affect interactions in small groups and thus the effectiveness of the group which, accordingly, affects productivity in constructing knowledge [44]. The question is whether $\mathrm{PBL}$ is an appropriate learning approach for interprofessional groups of students. Although interprofessional PBL was designed to foster collaborative, active learning skills in students, little is known about how it works in practice. This study aims to further clarify the inner workings of interprofessional PBL [45] and focus on examining constructive and collaborative activities among undergraduates taking part in an interprofessional PBL tutorial.

In order to achieve the aim of this study, we developed the following research questions:

1. To what extent do students in interprofessional PBL groups demonstrate constructive and collaborative activities in the tutorial group discussions?

2. To what extent do these activities differ between students from different professional groups?

3. How do the students reflect on their performance during interprofessional tutorial group discussions?

\section{Method \\ Context}

In Indonesia, all undergraduate health professions programmes have introduced interprofessional collaboration skills to their core curricula. However, very few Indonesian universities have actually incorporated an IPE programme that facilitates collaborative learning in interprofessional student teams into their curriculum. Universitas Islam Sultan Agung officially implemented IPE in 2017, and since 2012 has conducted several pilot projects on IPE, including interprofessional PBL tutorials and simulations for medical, nursing and midwifery programmes. The objectives of the IPE pilot project were to improve students' ability to collaborate, share and communicate patient information with different professionals as a member of a health care team and to present an appropriate treatment and care plan to 
address the patient's social, psychological and economic conditions.

Three healthcare education programmes are involved in the IPE pilot project, namely medical, nursing and midwifery programmes. These programmes differ in length and duration of their pre-clinical and clinical phases. While the medical and nursing programmes all have five-year curricula, the midwifery programme spans only 3 yrs. The clinical phases start after three and half pre-clinical years (medicine), 4 yrs (nursing), and two (Midwifery). Midwifery and nursing students have early clinical exposure in their pre-clinical phase in the form of 2 months of midwifery and nursing practice in a hospital or public health centre. Medical students do not have any practical experience in their pre-clinical years other than skills practice in the lab with simulated patients and manikins. Learning in all programmes is uniprofessional, meaning that students rarely collaborate with students from other healthcare disciplines, not even during clinical rotations. As a pedagogical approach, PBL has been applied in the curriculum of each program. Therefore students experience learning collaboratively in the uni-professional setting. However, they never experience sharing knowledge and expertise with students from another professional background. For the present pilot study we invited students in their final preclinical year of medical, nursing, and midwifery to participate.

\section{Interprofessional problem-based learning tutorial}

Uni-professional PBL tutorials have been applied in the programmes since 2005 , so students do not need to learn how to conduct tutorial discussions. The PBL tutorial applied in the health-related programmes of Sultan Agung Islamic University employs seven jump steps [46, 47].

\footnotetext{
PBL seven jump steps

Step 1. Identify and clarify unfamiliar terms presented in the scenario; the scribe lists the terms that remain unexplained after the discussion Step 2. Define the problem or problems to be discussed

Step 3. Use "brainstorming" to discuss the problem(s), suggesting possible explanations on the basis of prior knowledge; students draw on each other's knowledge and identify areas of incomplete knowledge Step 4. Review steps 2 and 3 and arrange explanations into tentative solutions; the scribe organizes the explanations and restructures if necessary

Step 5. Formulate learning objectives; group reaches consensus on the learning objectives

Step 6. Private study

Step 7. Students identify their learning resources and share the results of private study with group
}

Tutorial session 1 (T1), which lasted $100 \mathrm{~min}$, started by presenting the groups of students with the problems of clinical scenario. Through the group discussions and using prior knowledge of the content of the scenario, students identified learning issues (steps 1-5). After the discussion, students independently researched the learning issues outside the classroom (step 6). Students were given 3 days for self-directed learning. In this step, students have to study the learning issues related to both their areas of expertise and general medical science. For example, students had to study both the management and pathophysiology of pregnancy bleeding, including (other) risk factors of pregnancy. In tutorial session 2 (T2), which also lasted $100 \mathrm{~min}$, the students regrouped to share the results of their selfdirected learning (step 7).

Four scenarios (one per week) in the area of the reproductive system provided the topics of discussion. The background of the medical cases was interprofessional health care in a public health centre and the cases were problems that were commonly encountered in rural public health centres. The scenarios were treating: (1) tuberculosis (TB) during pregnancy, (2) vaginal bleeding during pregnancy in a public health setting, (3) hyperemesis gravidarum and (4) normal labour in a public health centre. For learning outcomes of the interprofessional PBL program, see Table 1.

\section{Research design}

We applied an explanatory, sequential mixed methods design to answer the research questions [48]. First we collected quantitative data on students' constructive collaborative activities in interprofessional PBL tutorials by observing the video-recordings and filling out a previously inter-rater reliability-checked Maastricht Peer-Activity Rating Scale (MPARS). The results of the scale were then used as input for qualitative data collection, which consisted of uni-professional focus group discussions aimed to understand the underlying reasons for students' perceptions of the interprofessional PBL tutorial. We also explored the students' perception of their own performance of constructive and collaborative activities during the interprofessional PBL tutorial.

\section{Quantitative data collection and analysis: MPARS}

All the tutorial processes were video-recorded. The recorders were set in the corner of the room to minimize any disruption to the participants' behaviour. To analyse the students' behaviour, we recorded 40 interprofessional PBL discussions (eight videos per group), resulting in approximately $67 \mathrm{~h}$ of video data.

To evaluate students' constructive, collaborative and motivational activities, Kamp [49] developed the Maastricht Peer-Activity Rating Scale (MPARS). Containing 14 items, this scale is intended for assessing 
Table 1 Learning outcomes

$$
\begin{aligned}
& \text { Week } 1 \\
& \text { Topic: Tuberculosis in pregnancy } \\
& \text { After attending the small group discussion tutorial, students were } \\
& \text { expected to be able to: } \\
& \text { - Explain the signs, symptoms and diagnosis of TB in pregnancyExplain } \\
& \text { the diagnostic procedure for TB in pregnancy } \\
& \text { • Explain the pharmacodynamics and pharmacokinetics of TB drugs } \\
& \text { and their side effects for pregnancy } \\
& \text { • Explain the role and responsibility of each profession of the health } \\
& \text { care team in handling a case of TB in pregnancy in the public health } \\
& \text { centre. }
\end{aligned}
$$

Week 2

Topic: Vaginal bleeding

After attending the small group discussion tutorial, students were expected to be able to:

- Determine the scientific basis relevant to the pathophysiological understanding of the occurrence of vaginal bleeding in the third trimester of pregnancy

- Describe the ethology and risk factors for vaginal bleeding in the third trimester of pregnancy

- Describe the symptoms, signs, complications and abnormality of vaginal bleeding in the third trimester of pregnancy

- Explain the differential diagnosis of vaginal bleeding in the third trimester of pregnancy

- Explain the treatment administered to stop the patient bleeding in a public health centre and what should be done to refer the patient to hospital

- Explain the role and responsibility of each profession of the health care team in handling vaginal bleeding in the third trimester of pregnancy case in the public health centre.

Week 3

Topic: Hyperemesis gravidarum

After attending the small group discussion tutorial, students were

expected to be able to:

- Explain the signs of emergency in pregnancy

- Explain how to provide first aid in cases of severe dehydration /

hypovolemic shock based on evidence-based medicine

- Explain the management of hyperemesis gravidarum

- Explain the role of each health profession in managing emergency

cases in a public health centre.

Week 4

Topic: Normal labour

After attending the small group discussion tutorial, students were expected to be able to:

- Explain the signs of labour

- Explain the complications of labour

- Explain the roles and responsibility of health care team members in

handling third stage of labour in a public health centre setting

- Explain the steps of collaboration among health care team members in handling normal labour in a public health centre setting

- Explain the resuscitation procedure for new-borns.

peer behaviour (constructive, collaborative and motivational activity) by students in uni-professional PBL tutorial discussions. In the present study, two tutors evaluated only the constructive and collaborative activities recorded on the videos of the interprofessional PBL tutorials. The constructive activities scale evaluates skills in co-constructing knowledge, such as summarizing, drawing distinctions between main and side issues, asking critical questions, correcting misconceptions, and contributing to a better understanding of knowledge. The collaborative activities scale evaluates collaborative performance during the discussion, such as a student's influence on group members, their responsibility to the group, their willingness to share information, and their commitment to the group. The MPARS scale was translated by means of a double back translation procedure to assess the consistency between the original and translated versions. This means that an EnglishIndonesian translator translated the English version of the questionnaire into Bahasa Indonesian, after which another translator translated this version back into English. The instrument uses a five-point Likert scale ranging from (1) completely disagree; (2) disagree; (3) neutral; (4) agree; and (5) completely agree.

MPARS as a peer assessment tool has never been used before in Indonesia, or in any other Asian context. We felt that, as a measuring tool carried out by peers, MPARS; like other peer assessment tools might create too many feelings of discomfort in a cultural setting where saving face and speaking up are not self-evident $[50,51]$ Considering the characteristics of Asian students who might be biased in conducting peer assessment, in contrast to previous studies using MPARS, in this study the evaluation of students' performance using MPARS was conducted by tutors rather than by students. Future research needs to explore how MPARS can be used as an effective peerassessment tool in Asian settings. One of the researchers and a second ratter (junior tutor) assessed the constructive and collaborative activities recorded on videos of the interprofessional PBL tutorial to determine inter-rater reliability of the MPARS scale. Prior to the evaluation, the researchers and raters agreed on the evaluation items, so no differences in giving scores was expected. The evaluation results were collected and statistically tested with the Kappa test to determine the reliability of each item. The reliability and validity test was conducted employing SPSS (IBM SPSS Statistic).

Any differences in performing constructive and collaborative activities between students from each profession (medical, nursing and midwifery) were evaluated based on the average MPARS-item score, employing the Kruskal-Wallis test followed by the Mann-Whitney U statistical test.

\section{Qualitative data collection and analysis \\ Verbatim transcripts of the tutorial group meetings}

To explore students' actual engagement in interprofessional PBL tutorial groups, conversational data of the tutorial sessions were transcribed. The verbatim transcripts were made in Indonesian and coded for content, applying the coding scheme based on Kamp's interaction analysis model [49].

The constructive and collaborative activity was evaluated from the discussion process. For the analysis we selected segments from the discussion of prior 
knowledge (step 3) in T1 and from sharing the results of self-directed learning (step 7) in T2, as in these steps the students discuss, share, argue, and present knowledge.

\section{Focus groups}

To gain a better understanding of students' perceptions of their performance and participation in interprofessional PBL tutorials, we organized three uniprofessional focus groups (FGs) at the end of pilot project. We deliberately chose not to mix students from different programmes to overcome potential barriers to communication and to encourage participation in the discussion. The focus group discussions were also videorecorded. A lecturer in community medicine (SY) and a medical educationist (DRA) who understood the concept and aims of the study facilitated the FGs with the aid of a discussion guide [52]. The purpose of this guide is to focus the discussion on the topic to be explored. The discussions were transcribed by an expert, and the verbatim transcript was coded for content without eroding the original content. Two experts in medical education EL and SY performed the thematic analysis. They independently evaluated the transcripts, first by open coding, and then developed and agreed on the coding categories, which they finally applied to the data. After this process, all members of the research team discussed the findings until they reached consensus. The data were analysed utilizing ATLAS.ti (version 7).

\section{Participants}

Students in their final year medical, nursing and midwifery programmes voluntarily participated in mixed profession tutorial groups consisting of $8-10$ students (Table 2).

\section{Results}

A total of 52 students from midwifery, nursing and medicine took part in the study (Table 3). Some students were absent for the discussions, particularly in the second, third and fourth weeks, due to other academic or non-academic commitments.

\section{MPARS inter-rater reliability and validity tests}

The Kappa statistical test results indicated that all items had slight agreement with a Kappa coefficient of 0.010.20 and $p<0.05$ (Table 4). The result of validity test indicated that all assessment items were valid to measure students' co-construction and collaboration activities. The coefficient of corrected item-total correlation of all items were higher than 0.266 (correlation coefficient for 52 subjects).

\section{Constructive activities}

Results indicated that medical students performed better on constructive activities than midwifery and nursing students. The result of the Kruskal-Wallis statistical test on all items of constructive activities indicated a significant difference in the constructive scores of students from different healthcare professions, $p=0.000$ (Table 5).

Mann-Whitney testing between each of the two groups indicated that for all scale items, the mean score of midwifery and nursing students was not significantly different $(p>0.05)$. Meanwhile, in all assessed items, there was a significant difference in the scores of medical students with that of midwifery students and nursing students $(p<0.05)$.

Based on the analysis of the videos and transcripts of the tutorial group meetings, students were actively involved in the discussion and contributed to a better understanding regardless of their professional background. However, depending on the topic, we saw differences in the extent to which different groups of students engaged. Medical students contributed the most in the discussion of physiology, pathophysiology and clinical reasoning to decide on a diagnosis or a differential diagnosis but less in management. Midwifery students also contributed to elaborating knowledge of physiology, pathophysiology, specifically pregnancy, and they were best in explaining the management and treatment for normal pregnancy, but they participated less in patient management other than normal pregnancy. Meanwhile, nursing students were very active in elaborating information when the topic concerned practical management and treatment of the patient, but were less active in the discussion of physiology, pathophysiology and clinical reasoning to decide a diagnose or a differential diagnose. Group members who did not answer questions or explain knowledge became active listeners. This could be observed from the fact that they paid close attention to the other group members' conversation, asked clarifying and

\begin{tabular}{|c|c|c|c|c|c|}
\hline Group & $\begin{array}{l}\text { Profession } \\
\text { of Tutor }\end{array}$ & $\begin{array}{l}\text { Number of } \\
\text { Medical } \\
\text { students }\end{array}$ & $\begin{array}{l}\text { Number of } \\
\text { Nursing } \\
\text { students }\end{array}$ & $\begin{array}{l}\text { Number of } \\
\text { Midwifery } \\
\text { students }\end{array}$ & $\begin{array}{l}\text { Total } \\
\text { participants }\end{array}$ \\
\hline $\begin{array}{l}\text { Group } \\
1\end{array}$ & Nurse & 3 & 4 & 3 & 10 \\
\hline $\begin{array}{l}\text { Group } \\
2\end{array}$ & Nurse & 4 & 4 & 3 & 11 \\
\hline $\begin{array}{l}\text { Group } \\
3\end{array}$ & Doctor & 3 & 5 & 3 & 11 \\
\hline $\begin{array}{l}\text { Group } \\
4\end{array}$ & Doctor & 3 & 5 & 2 & 10 \\
\hline $\begin{array}{l}\text { Group } \\
5\end{array}$ & $\begin{array}{l}\text { Midwife/ } \\
\text { Doctor }\end{array}$ & 3 & 4 & 3 & 10 \\
\hline Total & & 16 & 22 & 14 & 52 \\
\hline
\end{tabular}


Table 3 Demographic characteristics of the participants

\begin{tabular}{|c|c|c|c|c|c|c|}
\hline & \multicolumn{2}{|c|}{ Midwifery } & \multicolumn{2}{|c|}{ Nursing } & \multicolumn{2}{|c|}{ Medical } \\
\hline & $\mathrm{N}$ & $\%$ & $\mathrm{~N}$ & $\%$ & $\mathrm{~N}$ & $\%$ \\
\hline \multicolumn{7}{|l|}{ Gender } \\
\hline Male & 0 & 0 & 10 & 45.5 & 6 & 37.5 \\
\hline Female & 14 & 100 & 12 & 54.5 & 10 & 62.5 \\
\hline \multicolumn{7}{|l|}{ Admission } \\
\hline scholarship & 1 & 7.1 & 0 & 0 & 1 & 6.3 \\
\hline regular test & 13 & 92.9 & 22 & 100 & 15 & 93.7 \\
\hline \multicolumn{7}{|c|}{ Decision to study at the program } \\
\hline own preference & 14 & 100 & 18 & 81.8 & 14 & 87.5 \\
\hline encouraged by parents & 0 & 0 & 4 & 18.2 & 2 & 12.5 \\
\hline \multicolumn{7}{|c|}{ Experience in collaborating with students from other departments } \\
\hline Yes & 10 & 71.4 & 12 & 54.5 & 12 & 75 \\
\hline \multirow[t]{2}{*}{ No } & 4 & 28.6 & 10 & 45.5 & 4 & 25 \\
\hline & Mean & SD & Mean & SD & Mean & SD \\
\hline Age & 19.8 & 0.63 & 19.8 & 0.42 & 20.2 & 0.66 \\
\hline GPA (max score 4) & 3.14 & 0.39 & 2.98 & 0.26 & 3.3 & 0.48 \\
\hline
\end{tabular}

Table 4 Inter-rater reliability of MPARS

\begin{tabular}{|c|c|c|c|c|}
\hline \multirow[b]{2}{*}{ No } & \multirow[b]{2}{*}{ Constructive activity } & \multicolumn{2}{|c|}{ Reliability } & \multirow{2}{*}{$\begin{array}{l}\text { Validity } \\
\text { corrected item- } \\
\text { total correlation }\end{array}$} \\
\hline & & Kappa & $P$ & \\
\hline 1 & $\begin{array}{l}\text { Students were able to make } \\
\text { adequate summaries }\end{array}$ & 0.147 & 0.000 & 0.85 \\
\hline 2 & $\begin{array}{l}\text { Students were able to make a } \\
\text { distinction between the main and } \\
\text { side issues in the subject matter }\end{array}$ & 0.157 & 0.000 & 0.77 \\
\hline 3 & Students asked critical questions & 0.078 & 0.020 & 0.77 \\
\hline 4 & $\begin{array}{l}\text { Students corrected } \\
\text { misconceptions about the subject } \\
\text { matter }\end{array}$ & 0.156 & 0.000 & 0.78 \\
\hline \multirow[t]{2}{*}{5} & $\begin{array}{l}\text { Students contributed to a better } \\
\text { understanding of the subject }\end{array}$ & 0.094 & 0.026 & 0.72 \\
\hline & Collaborative activity & & & \\
\hline 6 & $\begin{array}{l}\text { Students had a positive influence } \\
\text { on the group }\end{array}$ & 0.154 & 0.000 & 0.83 \\
\hline 7 & $\begin{array}{l}\text { Students felt responsible for the } \\
\text { group }\end{array}$ & 0.108 & 0.000 & 0.75 \\
\hline 8 & $\begin{array}{l}\text { Students promoted collaboration } \\
\text { between group members }\end{array}$ & 0.057 & 0.018 & 0.65 \\
\hline 9 & $\begin{array}{l}\text { Students were willing to share } \\
\text { their information }\end{array}$ & 0.179 & 0.000 & 0.84 \\
\hline 10 & $\begin{array}{l}\text { Students were committed to the } \\
\text { group }\end{array}$ & 0.046 & 0.047 & 0.71 \\
\hline
\end{tabular}

Table 5 Constructive activities

\begin{tabular}{|c|c|c|c|c|c|c|c|}
\hline \multirow[t]{2}{*}{ Items } & \multicolumn{2}{|c|}{ Midwifery } & \multicolumn{2}{|c|}{ Nursing } & \multicolumn{2}{|c|}{ Medical } & \multirow{2}{*}{$\begin{array}{l}\text { p } \\
\text { Kruskal- } \\
\text { Wallis }\end{array}$} \\
\hline & Mean & SD & Mean & SD & Mean & SD & \\
\hline \multicolumn{8}{|l|}{ Constructive activity } \\
\hline $\begin{array}{l}\text { Students were able } \\
\text { to make adequate } \\
\text { summaries }\end{array}$ & 2.48 & 0.48 & 2.59 & 0.55 & 3.22 & 0.39 & 0.000 \\
\hline $\begin{array}{l}\text { Students were able } \\
\text { to make a } \\
\text { distinction between } \\
\text { the main and side } \\
\text { issues in the subject } \\
\text { matter }\end{array}$ & 2.94 & 0.53 & 2.89 & 0.50 & 3.22 & 0.31 & 0.000 \\
\hline $\begin{array}{l}\text { Students asked } \\
\text { critical questions }\end{array}$ & 2.66 & 0.63 & 2.59 & 0.43 & 3.05 & 0.40 & 0.000 \\
\hline $\begin{array}{l}\text { Students corrected } \\
\text { misconceptions about } \\
\text { the subject matter }\end{array}$ & 2.62 & 0.54 & 2.59 & 0.43 & 3.05 & 0.40 & 0.000 \\
\hline $\begin{array}{l}\text { Students } \\
\text { contributed to a } \\
\text { better } \\
\text { understanding of } \\
\text { the subject }\end{array}$ & 2.69 & 0.53 & 2.89 & 0.57 & 3.43 & 0.39 & 0.000 \\
\hline
\end{tabular}

probing questions, added further information, rephrased or summarized to check their understanding, and waited until a group member had done speaking before responding.

Quotes from discussions:

"In the case of inducing labour when the fetal heart rate is abnormal, we usually administer oxygen by mask and lay the mother on her side." (Midwifery student 3 )

"Why she should be treated with oxygen and laid on her side?" (Nursing student 5)

"When she's lying on her side, I think it's easier for the nutrients to enter the fetus." (Midwifery student 3)

"It just has to do with technique."(Midwifery student 1)

"I learned there are a few possible labour positions. One of them is lying on her side. The mother lies on her left or right side with one leg raised, and the other leg straight... The benefit of this position is that it reduces pain in the waist, helps lower high blood pressure, and accelerates the labour process. This position makes the blood delivery from mother to fetus run well through the placenta and then labour is more comfortable."(Medical student 4)

\section{Collaborative activities}

The result of the Kruskal-Wallis statistical test for all items on collaborative activities indicated a significant difference between the MPAR scores of students from 
different healthcare professions, $p=0.000$. The MannWhitney test between each group pointed out that for all scale items, the mean scores of midwifery and nursing students were not significantly different $(p>$ 0.05). Meanwhile, in all assessed items, there was a significant difference in the mean score of medical students with that of midwifery students and nursing students $(p<0.05)$ (Table 6).

Students encouraged and facilitated one another when they discussed the learning issues. Group members from different professions complemented others in answering learning issues. They were open to each other, feeling free to ask and argue their professional viewpoints, and also understood their limitations and strengths. In addition, the role of group leader switched from profession to profession. The leader stimulated shared responsibility for the learning in the tutorial groups and helped the discussion run smoothly.

Collaboration was also apparent when students in one group of various professionals helped one another find answers and solve problems instigated by the tutors' critical questions.

“... It's important to know that pregnant women get the same TB treatment as other TB patients. Pregnant women can take rifampicin, isoniazid, ethambutol, and pyrazinamide all safely. There are indeed side effects of the drugs, both mild and severe...." (Medical student 1)

"Pregnant and non-pregnant women get the same treatment?" (Tutor)

“... Except for streptomycin ... Pregnant women should not be given streptomycin because of its ototoxicity. It causes calcium levels to drop in the blood and extreme loss of body water so it's harmful to the fetus."(Medical student 1)

"That's for category 1 and 2 so this combination is for two-month treatment. After that the patient should undergo another sputum smear." (Nursing student 4)
The above example of collaboration indicates that conflict on conceptual knowledge can be resolved collaboratively among professions.

\section{Qualitative findings}

To address the research question 'how do the students reflect on their performance during interprofessional tutorial group discussions?' and to allow for a better understanding of the interprofessional PBL process, we organized uni-professional focus groups. Five main themes were identified, specifically: 1) Students learned from each other professions' knowledge, 2) asking critical questions is not always self-evident 3) correcting misunderstandings without causing offence 4) Factor affecting students participation, 5) persisting professional barriers.

\section{Students learned from each other professions' knowledge.}

During the focus group discussions, students said that they benefitted from the differences in the knowledge of each professional group, and that they were able to both provide and gain knowledge. Furthermore, it helped them understand the limitations of their own profession.

"It's good to meet students from different programmes. I learned a lot from other professions, like I learned the steps to handle emergency patients from the nursing students." (Medical student 3)

"I learned how to apply clinical reasoning to diagnose patients from medical students" (Nursing student 2)

Interestingly, the students discussed not only medically related topics, such as physiology, pathophysiology, diagnosis, and management but also the roles and responsibilities of each profession related to the cases. This enabled the students to learn about the boundaries between roles and also the limitations of their own role.

Table 6 Collaborative activities

\begin{tabular}{|c|c|c|c|c|c|c|c|}
\hline \multirow[t]{2}{*}{ Items } & \multicolumn{2}{|c|}{ Midwifery } & \multicolumn{2}{|c|}{ Nursing } & \multicolumn{2}{|c|}{ Medical } & \multirow{2}{*}{$\begin{array}{l}\text { p } \\
\text { Kruskal- } \\
\text { Wallis }\end{array}$} \\
\hline & Mean & SD & Mean & SD & Mean & SD & \\
\hline \multicolumn{8}{|l|}{ Collaborative activity } \\
\hline Students had a positive influence on the group & 3.12 & 0.39 & 3.22 & 0.5 & 3.54 & 0.34 & 0.000 \\
\hline Students felt responsible for the group & 3.35 & 0.53 & 3.47 & 0.48 & 3.66 & 0.25 & 0.002 \\
\hline Students promoted collaboration with group members & 3.37 & 0.29 & 3.42 & 0.40 & 3.64 & 0.31 & 0.000 \\
\hline Students were willing to share their information & 3.11 & 0.55 & 3.11 & 0.52 & 3.68 & 0.28 & 0.000 \\
\hline Students were committed to the group & 3.37 & 0.49 & 3.24 & 0.38 & 3.64 & 0.24 & 0.000 \\
\hline
\end{tabular}


"In IPE we learned what role each profession must play in collaborative healthcare. It's important so that responsibility can be shared and the patient can be treated quickly and correctly" (Nursing student 4)

\section{Asking critical questions is not always self- evident}

Some students asked critical questions, usually to broaden understanding or deepen the topic. Nevertheless, the posing of critical questions was strongly influenced by the role of the tutor who usually asked critical questions to challenge students and stimulate deep learning. However, in groups with a very dominant tutor, this person mostly posed the critical questions which consequently reduced the students' role in such constructive learning activities as searching for links between topics and understanding mechanisms/ theories by themselves. As a result, students tended to rely on the tutor's questions to develop the concept.

\section{"Can a dead baby possibly be delivered spontaneously?” (Tutor)}

"Do you mean the mother does not know that the baby has passed away?" (Midwifery student 5)

\section{"Yes. Dead for months, for example. Can it still be delivered spontaneously?" (Tutor)}

"I think the baby can be delivered spontaneously after it dies, but not [when it is dead] for as long as months, like you said." (Medical Student 2)

\section{"Have you ever heard of abortion?" (Tutor)}

"Yes" (All students)

\section{"What are the complications of abortion?" (Tutor)}

Some students explained that asking questions was not nice for classmates, as the classmates then had to give further explanation and elaborate on the concept that they were trying to explain to the class. Asking questions should be avoided to maintain a conducive and comfortable discussion situation.

"We loved adding information rather than asking for further explanation. We do that in uni-professional tutorial as well. It's common for us students... asking questions means challenging our mates to explain. It's putting a burden on them." (Medical student 6) "...we understand that asking further questions or for clarification' will broaden our knowledge and understanding, but as my friend said, it burdens our mates and gives them problems. That's why we try to avoid it. We let our tutor ask the critical questions and bring those questions to the table so that all students are responsible for answering collaboratively." (Medical student 2)

Students pointed out that asking critical questions was also regarded as creating conflict, which would arise when students held different points of view. In that situation, it was apparent that students would come to a quick consensus and agree to avoid the inconvenient situation caused by differences.

"Critical questions will only produce new problem to discuss, and will sometimes create conflict. We don't like conflict. We love doing smooth discussion. That [avoiding conflict] makes us feel comfortable in the small group discussion." (Midwifery student 1)

"Difference of opinion happens sometimes, but we don't want to make it worse. For me, I'd rather accept another professional's opinion, understand their point of view and try to compromise on the difference." (Medical student 5)

Moreover, the analysis of students' activity during interprofessional tutorials indicated that the group leaders, students who could be from any profession, generally drew the conclusions of the discussion. Some groups drew no conclusions and the chair simply asked the group members whether all had understood and agreed with the discussion content. When all participants agreed with the explanation, the discussion continued on to the next topic. When we explored this phenomenon later on, the focus group students explained that it was common practice: if all the explanations were clear and there were no differences in opinion, then they would immediately agree and just go on to the next question.

"When there are no conflicting views and all the explanation are clear and we agree with them, then don't think we need to sum up." (Nursing student 2)

\section{Correcting misunderstandings without causing offence}


Correcting misunderstandings of the concept also occurred during interprofessional discussion. The interesting thing was that students tended to correct misunderstandings in students from other professions indirectly, in a polite manner, for example by quoting information from a learning resource they had read, rather than expressing direct disapproval [criticism].

"OK, let's expand the topic... If the fetus died in the womb, what should the health care team do?" (Tutor)

“C-section?” (Nursing student 3)

"Induction?" (Midwifery student 1)

"Do you mean per vagina?" (Tutor)

"If the fetus dies in the womb, it will come out by itself as the fetus will be considered a foreign body by the pregnant body." (Midwifery student 2)

"I read in Achdiat 2004 that there are several ways to manage fetal death in the womb. Dilation or curettage can be administered for pregnancy less than 12 weeks gestation. For pregnancy over 12 weeks..." (Medical student 4)

The focus group students explained that correcting misconceptions by providing information from learning resources was done to avoid causing offence to another group member.

"It also happens with correcting mistakes. We correct misunderstandings in other profession students politely, by providing another perspective from medical resources. So we don't say directly that the other person's opinion is wrong. We try to be as polite as possible so that others won't be offended. I don't want to let other students in the other professions think that we, the medical students, are more powerful than them." (Medical student 3)

\section{Factors affecting students' participation}

\section{a. The role of tutor}

Some students in the focus group clarified the strong role of the tutor in constructive learning activities and mention that tutors were too active. However, some students said that they appreciated the tutor taking an active role.

"Our tutor is so active. She asks a lot. But I think it's good because it can expand the topic of discussion." (Midwifery student 3)

b. Social status

Another factor hampering constructive learning was the difference in social status of the health profession groups. According to the students, 'inequality' made them reluctant to criticize opinions and pose critical questions to other students.

"Sometimes we feel too uncomfortable to ask [questions]. Embarrassed, I feel like I lack knowledge, especially [compared] to medical students." (Midwifery student 5)

\section{Persisting professional barriers}

We observed an interesting phenomenon with regard to students' collaborative behaviour. Despite collaborating solidly in their interactions for several weeks, we still found professional barriers up until the last week of meetings. For example, students still clustered physically in accordance with their profession; especially midwifery students. When this was explored during the focus group, students said that the problem was closely related to confidence. Students felt secure when sitting beside a friend from the same profession so that they could discuss the answer to a problem based on their shared background of professional knowledge. Some students felt that the interprofessional class was quite stressful, because they had to maintain professional pride.

Bellow are some quotes from the focus group discussion that indicating insecurity during interprofessional PBL.

"Yes... we always sit beside each other. We feel confident, and feel that we can support each other if we sit side by side. So, if we have problem, we can negotiate with the others according to our scientific background." (Midwifery student 2)

"Sitting next to a student from the same background made us feel safe. The discussion was so tough for us, it forced us to struggle to do our best because we had to uphold the pride of our profession." (Nursing student 4) 


\section{Discussion}

Using a mixed methods design we set out to study how students engage in constructive collaboration in interprofessional PBL tutorial meetings, how the performance of each professional group differed and how students motivated their performance during the tutorials.

Based on the observations of the tutorials and using the MPARS, two researchers rated the students to distinguish those who very actively contributed to construct knowledge regardless of their professional background. These students collaborated on developing knowledge and complemented one another in answering the learning issues. They shared knowledge and learned about one another's professions, including the role boundaries and limitations. These findings suggest that the PBL setting meets the aims of IPE - to experience the perspectives held by others, to listen to the way they talk about their tasks and competencies and to construct knowledge in collaboration with one another [43, 53, 54]. Students were observed to correct each other's misconceptions interprofessionally. Very encouraging was the fact that corrections were voiced politely in non-confrontational language, indicating respect for the fellow student and potentially the other's profession. These findings resonate with previously reported studies which describe that interprofessional PBL could inculcate respect for other professions and appreciation of the roles and knowledge of others [32, 55].

Our findings provide examples of collaborative interprofessional practice when it comes to solving the patients' problem. Interestingly, conflict on conceptual knowledge can be elaborated collaboratively among the professions. Others have demonstrated how collaboration in PBL might have favourable outcomes for IPE because it helps in creating a more positive attitude towards other professional groups and improving interprofessional relations [32, 43, 53, 56, 57].

In addition to these promising findings, our results show that students often try to avoid conflicts in the discussion or, when conflicts arise, they accept sketchy arguments and conclude the discussion quickly. This could be problematic, as learning to cope with uncertainty is an essential goal in PBL and the ability to avoid hasty conclusions in uncertain situations is vital for future clinical practice [58]. However, these phenomena are also observed in uni-professional PBL [59]. Our findings imply that students' discussion skills need to be enhanced, such as the skills required to bring out differences in each other's conceptual thinking, to develop deep argumentation and to produce questions that elicit elaboration. The tutors' ability to facilitate collaborative resolution of conflicts in knowledge in the interprofessional tutorial should be improved.
It was also found that midwifery and nursing students scored between poor and average on their constructive activities lower than medical students' scores, pointing to unequal participation in the PBL sessions. Medical students also scored higher on their collaborative activities. The focus group findings shed light on factors hindering equal participation, such as cultural aspects, the students' perception of hierarchy in the field of health services, and lack of self-confidence.

The role of cultural practices in relation to the success of PBL has been previously described [29, 60]. Active learning techniques, such as the PBL tutorial, have gained popularity at medical schools in western countries. However, there are problems to be faced in executing the method, particularly among Asian students who are used to gaining knowledge passively through didactic lectures, being spoon-fed and memorizing knowledge without criticizing itThe successful application of the PBL methods in Asian schools is impeded by different cultural practices, such as the students' lack of confidence in sharing their opinions, reluctance to criticize and share a different point of view and their preference for classic, didactic lectures and memorizing facts rather than extracting problems from the cases by themselves [61, 62]. As a result, the benefits of $\mathrm{PBL}$ designed to train students to argue, criticize and co-construct knowledge are less than optimally achievable $([63,64]$. Our findings indicate that critical questions were seldom asked during the discussions. This could be caused by a combination of cultural and interprofessional factors. The resulting dominance of the tutor in these cases has also been previously reported $[60,65]$. Facilitating IPE is complex and demanding, which makes the faculty development of tutors in an IPE setting critical [66-68].

Lessons to be learned from this research are that students from various professions can benefit from PBL interprofessional activities, such as being able to collaborate in constructing knowledge and practicing communicating with other professions. Also, IPE PBL could teach the student the importance of respecting and fostering respect for the roles of other professions, taking advantage of working in a team to tackle complex, difficult problems and discussing a patientcentred approach to care. This finding was in accordance with previous research which explored students' perception regarding interprofessional education and reported that students were favourable to IPE [69]. However, in this study, interprofessional PBL did not succeed in creating more equality in the process as medical students were better at constructive and collaborative activities. This seems to be a result of the interplay between various complex factors, such as the influence of the Asian cultures that tend to be 
hierarchical and place doctors in higher positions in society, and problems with self-confidence and the students' learning preferences. Considering these findings, it is suggested that PBL should not be the only learning approach applied to IPE. It can be as useful starting point for students from different professions in the pre-clinical year phase to interact in IPE, but then it should be followed by simulation and work-based learning approaches. The recent study by Paradis \& Whitehead also suggests that interprofessional training only makes sense when applying practices in the workplace [28].

This study contributes to literature as it provides pedagogical implication through examining students' actual performance and reflection on their participation in interprofessional PBL. The limitation of this study was that it was a small pilot project with a relatively small group of participants from three programs only. They might not represent the performance and perceptions of all Indonesian healthcare professional students. Moreover, students participating were volunteers so they may have had a stronger interest in experiencing IPE. Future research should include explorational and observational designs to study students' performances within interprofessional PBL among large numbers of students.

\section{Conclusion}

Implementing interprofessional PBL could motivate students to engage in the co-construction of knowledge and other collaborative activities to solve patients' problems. However, because PBL is influenced by national and professional cultures, implementing PBL alone is probably not enough to achieve all the IPE goals. In the Asian context, we suggest that PBL should be followed by other learning approaches in the continuum of study in the professional health care curriculum. There was evidence from this study that MPARS was valid and reliable instrument to evaluate students' constructive and collaborative activities during interprofessional PBL. Further research could implement the MPARS as a peer-assessment tool and help improve the tutorial group process.

\section{Abbreviations}

FG: Focus group; FGD: Focus group discussion; GPA: Grade point average; IPE: Interprofessional education; KMO: Kaiser-Meyer-Olkin; MPARS: Maastricht Peer-Activity Rating Scale

\section{Acknowledgements}

The authors wish to thank the Directorate General of Higher Education, Ministry of Research, Technology and Higher Education, Republic of Indonesia, for funding the project; all students who participated in the study; Dian Apriliana Rachmawati (DAR) and Suryani Yulianti (SY) research associates of the Medical Education Unit (MEU) of the Faculty of Medicine, Universitas Islam Sultan Agung, for their assistance in conducting the study.

\section{Authors' contributions}

EL designed and performed the studies, analysed the data and drafted the manuscript. RS, DW and AS contributed to the study's conception and helped draft the manuscript. All authors reviewed and approved the final manuscript.

\section{Funding}

This project was funded by the Ministry of Research, Technology and Higher Education of Indonesia.

\section{Availability of data and materials}

Materials and supporting data are available for download on the website: https://drive.google.com/drive/folders/1iTTZCAJnXDKdrKHWWv7ZA2 pOKtryRAb All files may be used for research and education without further consent.

\section{Ethics approval and consent to participate}

Ethics approval and consent to participate in the study was approved by the Bioethics Committee for Medical/Health Research Faculty of Medicine Islamic University of Sultan Agung Semarang (Letter No. 290/XII/2013/Komisi Bioetik) and was conducted at Sultan Agung Islamic University, Semarang, Indonesia. Taking part in the study posed no physical risk to participants. The research team sent the research proposal and ethical clearance to the directors of health profession education programmes in the university and asked for their help to announce the programme to students. Those interested in joining the programme could contact the research team. The team explained the project to the interested students, the goals and benefits of the project and the students' responsibility on joining the project. Those who agreed to join had to fill in a consent form. Tutors with more than two years' experience were recruited from various disciplines. Their participation in the project was also voluntary.

\section{Consent for publication}

Not applicable.

\section{Competing interests}

The authors declare that they have no competing interests. The authors alone are responsible for the writing and content of this paper.

\section{Author details}

${ }^{1}$ Medical Education Unit, Faculty of Medicine, Universitas Islam Sultan Agung, Semarang, Indonesia. ${ }^{2}$ School of Health Professions Education, Faculty of Health, Medicine and Life Sciences, Maastricht University, Maastricht, The Netherlands. ${ }^{3}$ Department of Medical Education, Faculty of Medicine, Gadjah Mada University, Yogyakarta, Indonesia.

Received: 10 May 2019 Accepted: 9 September 2019

Published online: 18 September 2019

\section{References}

1. Fewster-Thuente $L$, Velsor-Friedrich B. Interdisciplinary collaboration for healthcare professionals. Nurs Adm Q. 2008;32(1):40-8.

2. Williams B, McCook F, Brown T, Palmero C, McKenna L, Scholes R, French J, McCall L. Are undergraduate health care students ready for interprofessional learning?: a cross-sectional attitudinal study. Journal of Allied Health Sciences and Practice. 2012;10(3):1-11.

3. Brock D, Abu-Rish E, Chia-Ru C, Hammer D, Wilson S, Vorvick L, Blondon K, Schaad D, Liner D, Zierler B. Interprofessional education in team communication: working together to improve patient safety. BMJ Quality Safety. 2013;22(5):414-23.

4. Olson $\mathrm{R}$, Bialocerkowski A. Interprofessional education in allied health: a systematic review. Med Educ. 2014;48:236-46.

5. Olupeliyawa AM, O'Sullivan AJ, Hughes C, Balasooriya CD. The teamwork mini-clinical evaluation exercise (T-MEX): a workplace-based assessment focusing on collaborative competencies in health care. Acad Med. 2014; 899(2):1-7.

6. Rowland P, Kitto S. Patient safety and professional discourses: implications for interprofessionalism. J Interprof Care. 2014;28(4):331-8.

7. Thistlehwaite JE, Forman D, Matthews LR, Rogers GD, Steketee C, Yassine T. Competencies and frameworks in interprofessional education: a comparative analysis. Acad Med. 2014;89(6):869-75. 
8. San Martin-Rodriguez L, Beaulieu M, D'amour D, Ferrada-Videla M. The determinants of successful collaboration: a review of theoretical and empirical studies. J Interprof Care. 2005;9(Suppl 1):132-47.

9. Suter E, Arndt J, Arthur N, Parboosingh J, Taylor E. Role understanding and effective communication as core competencies for collaborative practice. J Interprof Care. 2009;23(1):41-51.

10. Xyrichis A, Lowton K. What fosters or prevents inter professional team working in primary and community care? A literature review. Int J Nurs Stud. 2008:45(1):140-53.

11. WHO. Transforming and scaling up health professionals' education and training: World Health Organization guidelines. Switzerland: World Health Organization; 2013. p. 124.

12. Hall P, Weaver L. Interdisciplinary education and teamwork: a long and winding road. Med Educ. 2001;35:867-75.

13. Whitehead $\mathrm{C}$. The doctor dilemma in interprofessional education and care: how and why will physicians collaborate? Med Educ. 2007;41:1010-6.

14. Barr H. Interprofessional education: today, yesterday and tomorrow. London: The Learning and Support Network; 2002.

15. Reeves $\mathrm{S}$, Freeth $\mathrm{D}$. The London training ward: an innovative interprofessional learning initiative. J Interprof Care. 2002;16(1):41-52.

16. Lindblom P, Scheja M, Torell E, Astrand P, Fellander-Tsai L. Learning orthopaedics: assessing medical students' experiences of interprofessional training in an orthopaedic clinical education ward. J Interprof Care. 2007; 21(4):413-23.

17. Curran V, Sharpe D, Forristall J, Flynn K. Student satisfaction and perceptions of small group process in case-based interprofessional learning. Medical Teacher. 2008;30:431-3.

18. Goldberg L, Brown G, Mosack V, Fletcher P: Student reflections following exposure to a case-based interprofessional learning experience: preliminary findings. J Interprof Care 2014, early online:1-3.

19. Van Soeren M, Macmillan K, Cop S. Development and evaluation of interprofessional care practices through clinical simulation. J Interprof Care. 2009;23:304-6

20. Bradley P, Cooper S, Duncan F. A mixed-methods study of interprofessional learning of resuscitation skills. Med Educ. 2009;43:912-22.

21. Carbonaro M, King S, Taylor E, Satzinger F, Snart F, Drummond J. Integration of e-learning technologies in an interprofessional health science course. Medical Teacher. 2008:30:25-33.

22. Coleman M, Roberts K, Wulff D, Van Zyl R, Newton K. Interprofessional ambulatory primary care practice-based educational program. J Interprof Care. 2008;22(1):69-84

23. Barr H, Koppel I, Reeves S, Hammick M, Freeth D. Effective Interprofessional education argument, assumption and evidence. Oxford UK: Blackwell Publishing Ltd; 2005.

24. Freeth D, Hammick M, Reeves S, Koppel I, Barr H. Effective interprofessional education: development, delivery and evaluation. Oxford: Blackwell Publishing; 2005

25. Reeves S, Mann L. Key factors in developing and delivering interprofessional education. Int J Ther Rehabil. 2003;10(7):310-3.

26. Thistlethwaite J, Nisbet G. Interprofessional education: what's the point and where we're at.... Clinical Teacher. 2007:4:67-72.

27. Paradis $E$, Whitehead C. Louder than words: power and conflict in interprofessional education articles, 1954-2013. Med Educ. 2015;49:399407.

28. Paradis E, Whitehead C. Beyond the lamppost: a proposal for a fourth wave of education for collaboration. Acad Med. 2018;93(10):1457-63.

29. Imafuku R, Kataoka R, Mayahara M, Suzuki H, Saiki T. Students' experiences in interdisciplinary problem-based learning: a discourse analysis of group interaction. Interdisciplinary Journal of Problem-Based Learning. 2014;8(2).

30. Mann K, Mcfetridge-Durdle J, Martin-Misener R, Clovis J, Rowe R, Beanlands $H$, Sarria M. Interprofessional education for students of the health professions: the "seamless care" model. J Interprof Care. 2009;23(3):224-33.

31. McKee N, D'Eon M, Trinder K. Problem-based learning for inter-professional education: evidence from an inter-professional PBL module on palliative care. Can Med Educ J. 2013:4(1):e35-48.

32. Thompson C. Do interprofessional education and problembased learning work together? Clin Teach. 2010;7:197-201.

33. Dolmans DHJM, Schmidt HG. What do we know about cognitive and motivational effects of small group tutorials in problem-based learning? Adv Health Sci Educ. 2006;11(4):321-36.
34. Dolmans DHJM, De Grave W, Wolfhagen IHAP, van der Vleuten CPM. Problem-based learning: future challenges for educational practice and research. Med Educ. 2005;39(7):732-41.

35. Visschers-Pleijers AJSF, Dolmans DHJM, Leng BA, Wolfhagen IHAP, Vleuten CPM. Analysis of verbal interactions in tutorial groups: a process study. Med Educ. 2006:40(2):129-37.

36. Yew E, Chng E, Schmidt HG. Is learning in problem-based learning cumulative? Adv Health Sci Educ. 2011;16:449-64.

37. Yew E, Schmidt HG. What students learn in problem based Learing. Instr Sci. 2011;40(2):371-95.

38. Van der Linden J, Erkens G, Schmidt H, Renshaw P. Collaborative learning. Dordrecht. The Netherlands: Kluwer; 2000.

39. McKee N, Goodridge D, Remillard F, D'eon M. Interprofessional palliative care problem-based learning: evaluation of a pilot module as a teaching and learning method. J Interprof Care. 2010;24(2):194-7.

40. D'Eon M, Proctor P, Cassidy J, McKee N, Trinder K. Evaluation of an Interprofessional problem-based learning module on Care of Persons Living with HIV/AIDS. J Res Interprof Prac Educ. 2010;1(2):109-26.

41. Imafuku R, Kataoka R, Mayahara M, Suzuki H, Saiki T. Students' experiences in interdisciplinary Problembased learning: a discourse analysis of group interaction. Interdisciplinary Journal of Problem-Based Learning. 2014;8(2):1-18.

42. Goelen G, Clercq GD, Huyghens L, Kerckhofs E. Measuring the effect of interprofessional problem-based learning on the attitudes of undergraduate health care students. Med Educ. 2006;40:555-61.

43. Dreier-Wolfgramm A, Homeyer S, Oppermann RF, Hoffmann W. A model of interprofessional problem-based learning for medical and nursing students: implementation, evaluation and implications for future implementation. GMS J Med Educ. 2018;35:1):1-20.

44. Singaram V, Van der Vleuten C, Muijtjens A, Dolmans D. Relationships between language background, secondary school scores, tutorial group processes, and students' academic achievement in PBL testing a causal model. Interdisciplinary Journal of Problem-Based Learning. 2012;6(1):153-4.

45. Cook DA, Bordage G, Schmidt HG. Description, justification and clarification: a framework for classifying the purposes of research in medical education. Med Educ. 2008:42:128-33.

46. Dolmans $D$, Wolfhagen $H$, van der Vleuten C. Motivational and cognitive processes influencing tutorial groups. Acad Med. 1998;73(10):22-4.

47. Wood DF. ABC of learning and teaching in medicine problem based learning. Clin Rev. 2003;326:328-30.

48. Johnson RB, Onwuegbuzie AJ. Mixed methods research: a research paradigm whose time has come. Educ Res. 2004;33(7):14-26.

49. Kamp RJA, Dolmans DHJM, Berkel HJMV, Schmidt HG. Can students adequately evaluate the activities of their peers in PBL? Medical Teacher. 2011:33:145-50

50. Papinczak T, Young L, Groves M. Peer assessment in problem-based learning: a qualitative study. Adv Health Sci Educ. 2007;12:169-86.

51. Sluijsmans DM, Moerkerke G, JJV M, Dochy FJ. Peer assessment in problem based learning. Studiesin Educational Evaluation. 2001;27:152-73.

52. Sarantakos S. Social research, 4th edn. Basingstoke: Palgrave Macmillan; 2012

53. Dahlgren LO. Interprofessional and problem-based learning: a marriage made in heaven? J Interprof Care. 2009;23(5):448-54

54. Chou FC, Kwan C-Y, Hsin DH-C. Examining the effects of interprofessional problem-based clinical ethics: findings from a mixed methods study. J Interprof Care. 2016;30(3):362-9.

55. Solomon $\mathrm{P}$, Salvatori $\mathrm{P}$, Guenter D. An interprofessional problem-based learning course on rehabilitation issues in HIV. Medical Teacher. 2003;25: 408-13.

56. L'Ecuyer K, Pole D, Leander SA. The use of PBL in an Interprofessional education course for health care professional students. Interdisciplinary Journal of Problem-Based Learning. 2015;9(1):8-18.

57. Goelen G, De Clercq G, Huyghens L, E K: Measuring the effect of interprofessional problem-based learning on the attitudes of undergraduate health care students. Med Educ 2006, 40 555-561.

58. Koh GC-H, Khoo HE, Wong ML, Koh D. The effects of problem-based learning during medical school on physician competency: a systematic review. Can Med Assoc J. 2008:178(1):34-41.

59. Aarnio M, Lindblom-Ylanne S, Nieminen J, Pyorala E. Dealing with conflicts on knowledge in tutorial groups. Advances in Health Science Education. 2013:18:215-30. 
60. Khoo H. Implementation of problem-based learning in Asian medical schools and students' perceptions of their experience. Med Educ. 2003; 37(5):401-9.

61. Frambach JM, Driessen EW, Chan L-C, CPMvd V. Rethinking the globalisation of problem-based learning: how culture challenges self-directed learning. Med Educ. 2012;46:738-47.

62. Waterval D, Tinnemans-Adriaanse M, Meziani M, Driessen E, Scherpbier A, Mazrou A, Frambach J. Exporting a student-centered curriculum: a home Institution's perspective. J Stud Int Educ. 2017;21(3):278-90.

63. Yeo S, Chang BH. Implementation of problem-based learning in medical education in Korea. Korean J Med Educ. 2017;29(4):271-82.

64. Iwata K, Doi A. Can hybrid educational activities of team and problem based learning program be effective for Japanese medical students? Kobe J Med Sci. 2017;63(2):E51-7.

65. Lekalakala-Mokgele E. Facilitation in problem-based learning: experiencing the locus of control. Nurse Educ Today. 2010;30:638-42.

66. Lindqvist SM, Reeves S. Facilitators' perceptions of delivering interprofessional education: a qualitative study. Medical Teacher. 2007;29: 403-5.

67. Jewell LM, D'Eon M, McKee N, Proctor P, Trinder K. Tutor experiences with facilitating Interprofessional problem-based learning. Journal of Research in Interprofessional Practice and Education. 2013;3(2):1-23.

68. Newton C, Wood V. Reflections on facilitating an interprofessional problembased learning module. J Interprof Care. 2009;23(6):672-5.

69. Lestari E, Stalmeijer R, Widyandana D, Scherpbier AJJA. Understanding students' readiness for interprofessional learning in an Asian context: a mixed-methods study. BMC Medical Education. 2016;16(179):1-11.

\section{Publisher's Note}

Springer Nature remains neutral with regard to jurisdictional claims in published maps and institutional affiliations.

Ready to submit your research? Choose BMC and benefit from:

- fast, convenient online submission

- thorough peer review by experienced researchers in your field

- rapid publication on acceptance

- support for research data, including large and complex data types

- gold Open Access which fosters wider collaboration and increased citations

- maximum visibility for your research: over $100 \mathrm{M}$ website views per year

At $\mathrm{BMC}$, research is always in progress.

Learn more biomedcentral.com/submissions 